\title{
CHEMICAL VARIABILITY OF Allamanda cathartica L. FLOWERS ASSESSED BY MULTIVARIATE DATA ANALYSIS
}

Deivisson W. Rodrigues ${ }^{\mathrm{a}}$, Ana Flavia F. Mullera, Tiago J. Bonomini ${ }^{\mathrm{a}}$, Luiz C. Klein-Júnior ${ }^{\mathrm{a}}$, Ruth M. Lucinda-Silva ${ }^{\mathrm{a}}$ and Angela Malheiros*,a, (i)

aNúcleo de Investigações Químico-Farmacêuticas, Universidade do Vale do Itajaí, 88302-202 Itajaí - SC, Brasil

Recebido em 29/08/2019; aceito em 06/11/2019; publicado na web em 21/01/2020

\begin{abstract}
The aim of this study was to determine the chemical variability of Allamanda cathartica flowers collected in different localities of Santa Catarina State, Brazil. Extractive solutions ( 25 samples) were analyzed by HPLC-DAD for the qualitative and quantitative profiles of the iridoid plumieride, the flavonoid rutin as well as total flavonoid content expressed in rutin. The chemical variability was evaluated by Principal Component Analysis (PCA) and Hierarchical Clustering Analysis (HCA). The samples demonstrated similar chromatographic profiles. In PCA analysis, Araquari samples AC01, AC08 and AC25 did not group with other samples obtained from other locations. In the HCA analysis, it was possible to observe hierarchially similar groups, generating 5 clusters. Group 5 (samples AC01, AC08 and AC25) presented lower similarity compared to the other groups. This dissimilarity can be explained by the amount of metabolites from each collection. Regarding the content of markers, it was observed a variation between 27 to $230 \mathrm{mg} / \mathrm{g}, 2.7$ to $9.5 \mathrm{mg} / \mathrm{g}$ and 7.14 to $17.8 \mathrm{mg} / \mathrm{g}$ for plumieride, rutin, and total flavonoids, respectively. The samples from Araquari (AC01, AC08, AC25) presented the highest concentrations of chemical markers. Therefore, for reproducibility and standardization of A. cathartica flower extracts, it is important to determine the location and the plant cultivation conditions.
\end{abstract}

Keywords: plumieride; rutin; multivariate data analysis; quality control.

\section{INTRODUCTION}

Allamanda cathartica L., popularly known as yellow alamanda or lady thimble, is a latex producer subshrub. This species is easily found in the different regions of Brazil and blooms in spring and summer. ${ }^{1}$ Pharmacological activities such as anti-inflammatory, ${ }^{2}$ antimicrobial, ${ }^{3}$ antifungal ${ }^{4}$ and wound healing ${ }^{5}$ are described in the literature. The flowers are constituted mainly by sugars, flavonoids, as rutin, and high content of the iridoid plumieride..$^{6,7}$

Plumieride is an iridoid of great interest because of its biological potential as reported anti-inflammatory activity ${ }^{8,9}$ and inhibitory fungi growth. ${ }^{10}$ Rutin is one of the major flavonoids in extracts of flowers of $A$. cathartica and its pharmacological potential as antioxidant, antiviral, antihypertensive and auxiliary in the treatment of type 2 diabetes ${ }^{11}$ has been described.

The secondary metabolism can vary significantly depending on the conditions that the plants are exposed such as seasonality, rainfall index, UV radiation, altitude, temperature, circadian rhythm, atmospheric composition, herbivory, age, micro, and macronutrients. In addition, factors such as collection, stabilization and storage conditions can influence the quality and biological activity of herbal extracts. ${ }^{12}$

Taking into account the potential application of $A$. cathartica flowers extract in pharmaceuticals and cosmetics industry and the influence of geoenvironmental factors in the production of secondary metabolites, the present work evaluated the qualitative chemical profile and rutin and plumieride contents in the flower extracts of $A$. cathartica collected in different localities.

\section{EXPERIMENTAL}

\section{Plant material}

Flowers of Allamanda cathartica L. were collected in the period from January to March 2017. In the Itajaí Valley region, collections were obtained in the cities of Balneário Camboriú (AC17, AC18, AC19), Bombinhas (AC16), Blumenau (AC11, AC12), Brusque (AC14, AC22), Camboriú (AC20), Itajaí (AC02, AC09, AC10, AC15), Itapema (AC21), Luiz Alves (AC23), Navegantes (AC13), Penha (AC06, AC07) and Porto Belo (AC24). In the Northern region, collections were obtained in Araquari (AC01, AC08, AC25) and Joinville (AC03); and in the Southern region, in Imbituba (AC05) and Morro da Fumaça (AC04). The geographic location of the samples is presented in Table 1.

The flowers were identified by Professor Renê Arthur Ferreira and a voucher from the city of Araquari was deposited at Barbosa Rodrigues Herbarium (Itajaí - Brazil) under the number HBR 52742.

The access to the botanical material was registered in Sistema Nacional de Gestão do Patrimônio Genético e do Conhecimento Tradicional Associado (SISGEN) under number A263FC4, as required by Brazilian legislation.

The plant material was dried in an oven at $35^{\circ} \mathrm{C}$ for seven days, pulverized and stored at $-20{ }^{\circ} \mathrm{C}$ until use.

\section{Extracts preparation}

The hydroethanolic extracts were prepared by dynamic maceration with ethanol-water 90:10 (v/v), at a plant:solvent ratio 1:30 (w/v), which was stirred for six hours at $300 \mathrm{rpm}$ and filtered. The extractive solutions were prepared in triplicate.

The dry residue was determined using the procedure described in the Brazilian Pharmacopoeia. ${ }^{13}$ A solution sample $(5 \mathrm{ml})$ was transferred to desiccated crucibles. The solutions were evaporated on a hotplate and subsequently desiccated for 3 hours in an oven at $105{ }^{\circ} \mathrm{C}$. After desiccation, the crucibles were weighed and the dry residue calculated and expressed as \% w/v. Analyzes were performed in triplicate.

*e-mail: angela@univali.br 


\section{HPLC analysis}

Liquid chromatographic analysis was performed on a Shimadzu LC-20AT chromatograph (Shimadzu, Tokyo, Japan), consisting of a binary pump with scan detector and photodiode spectrum, oven and automatic injector. The method was previously established by Muller et $a l .{ }^{6}$ A Phenomenex Luna C18 $(250 \times 4.6 \mathrm{~mm})$ reverse phase column (Torrance, California, USA) was used, eluted with acetonitrile (A) and acidic water pH 3.5 (B) 15:85 (A:B, v/v) at time zero, 30:70 from 0 to 10 minutes and 15:85 from 10 to 25 minutes, with constant flow of $1.0 \mathrm{~mL} \mathrm{~min}^{-1}$, at $30{ }^{\circ} \mathrm{C} .20 \mu \mathrm{L}$ of each sample was injected in triplicate and detection was performed at $230 \mathrm{~nm}$, $355 \mathrm{~nm}$ and $265 \mathrm{~nm}$.

Samples were diluted with 1:10 methanol and analyzed in triplicate. Plumieride concentration was determined using the plumieride analytical curve (linearity between 10 to $750 \mu \mathrm{g} \mathrm{mL} \mathrm{m}^{-1}$, $\left.y=26368 x-58577 r^{2}=0.999\right){ }^{6}$ While, rutin and total flavonoids contents were determined using rutin analytical curve (linearity between 10 to $\left.50 \mu \mathrm{g} / \mathrm{mL}, \mathrm{y}=38015 \mathrm{x}-29734 \mathrm{r}^{2}=0.999\right){ }^{6}$

\section{Multivariate data analysis}

Unsupervised data analysis, Principal Component Analysis (PCA) and Hierarchical Clustering Analysis (HCA), were performed in Matlab ${ }^{\text {TM }}$ 2013b (The Mathworks, MA, USA). The average HPLC fingerprints of each sample was organized to obtain a matrix $(X)$, where the rows represented the number of samples and the columns, the number of time points, containing the intensity at $265 \mathrm{~nm}$. This wavelength was selected because it is possible to detect both flavonoids and iridoids. To align the peaks, matrix $X$ was pre-processed, using correlation optimized warping (COW). It allows the stretching and compression of the data to allow fitting the chromatogram to align $(P)$ to the target chromatogram $(T) .{ }^{14}$

\section{RESULTS AND DISCUSSION}

In total, 25 samples of the flowers of A. cathartica were obtained in the North, Itajaí Valley and South regions of Santa Catarina State, Brazil. The collections were intensified in the Itajaí Valley region due to disponibility and easy access.

According to the results presented in Table 1, A. cathartica extractive solutions did not show significant differences in dry residue values, indicanting that the plant collected in different localities has similar content, with an average value of $14 \mathrm{mg} / \mathrm{g}$. The determination of the dry residue allowed to know the extraction potential of the solvent used, as well as the similarity of the chemical composition because in this analysis is determined the substances dissolved by the extraction solvent used.

Table 1. Samples identification and results of dry residue and plumieride, rutin and total flavonoids contents in A. cathartica flowers extractive solutions. Results expressed in average \pm standard deviation

\begin{tabular}{|c|c|c|c|c|c|}
\hline Samples & Geographic Location & Dry residue $(\% \mathrm{w} / \mathrm{v})$ & Plumieride (mg/g) & Rutin (mg/g) & Total flavonoids ${ }^{1}(\mathrm{mg} / \mathrm{g})$ \\
\hline $\mathrm{AC} 01$ & $26^{\circ} 34^{\prime} 57.1^{\prime \prime} \mathrm{S} 48^{\circ} 41^{\prime} 51.9^{\prime \prime} \mathrm{W}$ & $9.17 \pm 0.04$ & $229.13 \pm 0.05$ & $9.50 \pm 0.65$ & $17.83 \pm 0.96$ \\
\hline $\mathrm{AC} 02$ & $26^{\circ} 54^{\prime} 58.8^{\prime \prime} \mathrm{S} 48^{\circ} 39^{\prime} 54.0^{\prime \prime} \mathrm{W}$ & $13.25 \pm 0.03$ & $130.72 \pm 0.04$ & $4.12 \pm 0.07$ & $11.02 \pm 0.32$ \\
\hline $\mathrm{AC} 03$ & $26^{\circ} 16^{\prime} 03.5^{\prime \prime} \mathrm{S} 48^{\circ} 51^{\prime} 47.5^{\prime \prime} \mathrm{W}$ & $11.30 \pm 0.08$ & $69.11 \pm 0.02$ & $3.25 \pm 0.07$ & $9.44 \pm 1.27$ \\
\hline $\mathrm{AC} 04$ & $28^{\circ} 35^{\prime} 50.1^{\prime \prime} \mathrm{S} 49^{\circ} 14^{\prime} 47.7^{\prime \prime} \mathrm{W}$ & $15.14 \pm 0.04$ & $103.05 \pm 0.04$ & $4.37 \pm 0.24$ & $11.74 \pm 0.22$ \\
\hline $\mathrm{AC} 05$ & $28^{\circ} 07^{\prime} 47.3^{\prime \prime} \mathrm{S} 48^{\circ} 38^{\prime} 31.8^{\prime \prime} \mathrm{W}$ & $15.57 \pm 0.02$ & $95.66 \pm 0.19$ & $4.17 \pm 0.51$ & $10.84 \pm 1.25$ \\
\hline AC06 & $26^{\circ} 46^{\prime} 60.0^{\prime \prime} \mathrm{S} 48^{\circ} 37^{\prime} 57.8^{\prime \prime} \mathrm{W}$ & $15.83 \pm 0.09$ & $105.58 \pm 0.04$ & $6.18 \pm 0.41$ & $15.11 \pm 0.71$ \\
\hline $\mathrm{AC} 07$ & $26^{\circ} 47^{\prime} 54.5^{\prime \prime} \mathrm{S} 48^{\circ} 36^{\prime} 58.5^{\prime \prime} \mathrm{W}$ & $14.92 \pm 0.01$ & $116.74 \pm 0.09$ & $6.68 \pm 0.15$ & $14.90 \pm 1.67$ \\
\hline $\mathrm{AC} 08$ & $26^{\circ} 34^{\prime} 57.1^{\prime \prime} \mathrm{S} 48^{\circ} 41^{\prime} 51.9^{\prime \prime} \mathrm{W}$ & $14.95 \pm 1.94$ & $230.39 \pm 0.03$ & $7.39 \pm 0.22$ & $13.70 \pm 0.22$ \\
\hline $\mathrm{AC} 09$ & $26^{\circ} 55^{\prime} 29.5^{\prime \prime} \mathrm{S} 48^{\circ} 38^{\prime} 48.0^{\prime \prime} \mathrm{W}$ & $14.44 \pm 1.72$ & $105.37 \pm 0.12$ & $4.74 \pm 0.62$ & $13.36 \pm 1.62$ \\
\hline $\mathrm{AC} 10$ & $26^{\circ} 55^{\prime} 15.0^{\prime \prime} \mathrm{S} 48^{\circ} 39^{\prime} 51.8^{\prime \prime} \mathrm{W}$ & $13.11 \pm 3.48$ & $111.30 \pm 0.05$ & $2.78 \pm 0.09$ & $7.14 \pm 0.19$ \\
\hline $\mathrm{AC} 11$ & $26^{\circ} 52^{\prime} 24.1^{\prime \prime} \mathrm{S} 49^{\circ} 06^{\prime} 23.8^{\prime \prime} \mathrm{W}$ & $13.51 \pm 3.96$ & $94.49 \pm 0.04$ & $2.97 \pm 0.23$ & $8.31 \pm 0.23$ \\
\hline $\mathrm{AC} 12$ & $26^{\circ} 54^{\prime} 38.7^{\prime \prime} \mathrm{S} 49^{\circ} 04^{\prime} 50.9^{\prime \prime} \mathrm{W}$ & $13.75 \pm 3.47$ & $114.26 \pm 0.04$ & $3.34 \pm 0.14$ & $9.22 \pm 0.22$ \\
\hline $\mathrm{AC} 13$ & $26^{\circ} 49^{\prime} 41.5^{\prime \prime} \mathrm{S} 48^{\circ} 37^{\prime} 49.5^{\prime \prime} \mathrm{W}$ & $14.29 \pm 1.90$ & $27.30 \pm 0.03$ & $3.75 \pm 0.44$ & $10.08 \pm 0.88$ \\
\hline $\mathrm{AC} 14$ & $27^{\circ} 06^{\prime} 19.7^{\prime \prime} \mathrm{S} 48^{\circ} 55^{\prime} 43.6^{\prime \prime} \mathrm{W}$ & $14.23 \pm 2.15$ & $88.69 \pm 0.03$ & $4.49 \pm 0.31$ & $12.81 \pm 0.47$ \\
\hline $\mathrm{AC} 15$ & $26^{\circ} 53^{\prime} 34.7^{\prime \prime} \mathrm{S} 48^{\circ} 40^{\prime} 32.8^{\prime \prime} \mathrm{W}$ & $14.33 \pm 2.48$ & $105.99 \pm 0.09$ & $2.93 \pm 0.21$ & $8.44 \pm 0.50$ \\
\hline $\mathrm{AC} 16$ & $27^{\circ} 10^{\prime} 36.2^{\prime \prime} \mathrm{S} 48^{\circ} 31^{\prime} 51.0^{\prime \prime} \mathrm{W}$ & $13.53 \pm 1.14$ & $109.15 \pm 0.05$ & $3.93 \pm 0.27$ & $11.98 \pm 0.31$ \\
\hline $\mathrm{AC} 17$ & $27^{\circ} 02^{\prime} 12.0^{\prime \prime} \mathrm{S} 48^{\circ} 35^{\prime} 00.9^{\prime \prime} \mathrm{W}$ & $15.08 \pm 3.70$ & $125.58 \pm 0.05$ & $3.76 \pm 0.37$ & $11.73 \pm 0.28$ \\
\hline $\mathrm{AC} 18$ & $27^{\circ} 01^{\prime} 19.6^{\prime \prime} \mathrm{S} 48^{\circ} 35^{\prime} 01.0^{\prime \prime} \mathrm{W}$ & $14.53 \pm 3.66$ & $128.14 \pm 0.17$ & $3.95 \pm 0.84$ & $11.55 \pm 1.87$ \\
\hline AC19 & $26^{\circ} 59^{\prime} 44.6^{\prime \prime} \mathrm{S} 48^{\circ} 35^{\prime} 50.1^{\prime \prime} \mathrm{W}$ & $14.84 \pm 2.50$ & $133.45 \pm 0.05$ & $3.00 \pm 0.10$ & $9.66 \pm 0.24$ \\
\hline AC20 & $27^{\circ} 01^{\prime} 33.1^{\prime \prime} \mathrm{S} 48^{\circ} 39^{\prime} 32.7^{\prime \prime} \mathrm{W}$ & $14.76 \pm 1.11$ & $157.42 \pm 0.04$ & $7.52 \pm 0.40$ & $17.30 \pm 0.39$ \\
\hline $\mathrm{AC} 21$ & $27^{\circ} 04^{\prime} 01.4^{\prime \prime} \mathrm{S} 48^{\circ} 35^{\prime} 46.4^{\prime \prime} \mathrm{W}$ & $14.17 \pm 2.63$ & $133.11 \pm 0.07$ & $5.50 \pm 0.56$ & $14.67 \pm 0.78$ \\
\hline $\mathrm{AC} 22$ & $27^{\circ} 03^{\prime} 18.5^{\prime \prime} \mathrm{S} 48^{\circ} 52^{\prime} 20.4^{\prime \prime} \mathrm{W}$ & $14.48 \pm 2.66$ & $99.40 \pm 0.04$ & $6.79 \pm 0.25$ & $15.36 \pm 0.78$ \\
\hline $\mathrm{AC} 23$ & $26^{\circ} 43^{\prime} 04.3^{\prime \prime} \mathrm{S} 48^{\circ} 51^{\prime} 00.9^{\prime \prime} \mathrm{W}$ & $13.29 \pm 2.23$ & $93.68 \pm 0.01$ & $3.72 \pm 0.30$ & $11.46 \pm 0.43$ \\
\hline $\mathrm{AC} 24$ & $27^{\circ} 09^{\prime} 34.6^{\prime \prime} \mathrm{S} 48^{\circ} 34^{\prime} 15.4^{\prime \prime} \mathrm{W}$ & $13.92 \pm 1.25$ & $78.53 \pm 0.04$ & $5.82 \pm 0.16$ & $14.20 \pm 0.49$ \\
\hline $\mathrm{AC} 25$ & $26^{\circ} 34^{\prime} 57.1^{\prime \prime} \mathrm{S} 48^{\circ} 41^{\prime} 51.9^{\prime \prime} \mathrm{W}$ & $13.66 \pm 0.62$ & $224.20 \pm 0.21$ & $7.02 \pm 0.29$ & $12.58 \pm 0.56$ \\
\hline
\end{tabular}

${ }^{1}$ Total flavonoids expressed in rutin equivalent concentration. 
Extractive solutions obtained from different collections were analyzed by HPLC using the method established by Muller et al. ${ }^{6}$ Initially, chromatograms at different wavelengths were analyzed to identify the qualitative profile. The wavelengths of 230 and $355 \mathrm{~nm}$ were selected for quantitative analysis of plumieride and flavonoids, respectively. To perform the correlations using multivariate analysis, the wavelength of $265 \mathrm{~nm}$ was selected. Figure 1A shows the chromatogram of one of the Itajaí (AC02) collections. The peak with retention time at 9.9 minutes, with maximum absorption at $213 \mathrm{~nm}$, refers to plumieride. This iridoid is the major compound of flower extracts as described in the previous studies. ${ }^{6,7}$ In Figure 1B, the peak at the retention time of 12.0 minutes refers to rutin, as identified in the UV spectrum, showing three maximum absorption peaks at $204 \mathrm{~nm}$, $255 \mathrm{~nm}$, and $355 \mathrm{~nm}$. Two other peaks with retention time at 12.9 and 13.1 minutes also have an absorption profile similar to rutin, which may be inferred as flavonoids.

The chromatographic profiles of the extractive solutions analysed at $265 \mathrm{~nm}$ were overlapped in Figure 2. The results show the samples fingerprints. However, overlaps also show differences in peak intensity and this might be related to the concentration of secondary metabolites present in the different solutions.

Hierarchical Cluster Analysis (HCA) and Principal Component Analysis (PCA) were obtained from the matrix generated by the average chromatogram of two or more samples of the evaluated extracts. Figure 3 shows the PCA. Each sample is represented by a dot on the chart. Dots 1, 8 and 25 represent samples AC01, AC08, and AC25 from Araquari city. These samples do not cluster with samples obtained from other localities, mainly separated by PC2. Although some minor cluster tendency can be observed for other samples, they were not confirmed by HCA (Figure 4), demonstrating that their separation by unsupervised methods is not accessible, suggesting some homogeneity in the remaining samples.

Figure 4 shows the HCA of all samples made using the Euclidean distance. The analysis allowed to identify similar groups in a hierarchical way. In group 1 the samples from Southern Region of Santa Catarina State and some from Itajaí Valley are grouped. In groups 2 and 3 only samples from the Itajaí Valley region are grouped. Group 4 is composed of some collections from Itajaí Valley and Northern Region, while group 5 is composed only of samples from Northern Santa Catarina State. Analyzing the clusters, group 5 presented lower similarity compared to the others, being composed by Araquari samples (AC01, AC08, and AC25). Such dissimilarity presented by group 5 might be explained by secondary metabolites content.

After multivariate analysis, it was necessary to evaluate possible differences of the extractive solutions in relation to the quantitative composition of the metabolites for each collection. The chromatogram peaks were integrated to determine the concentration of plumieride at $230 \mathrm{~nm}$ and flavonoids at $355 \mathrm{~nm}$, obtaining the proportion of the areas. Concentrations were obtained using the analytical curve of the compounds separately, as described by Muller et al. ${ }^{6}$

The concentration values for plumieride, rutin, and total flavonoids are described in Table 1 .

The quantification of the secondary metabolites showed that, although there are variations among the different samples, the

(A) $230 \mathrm{~nm}$
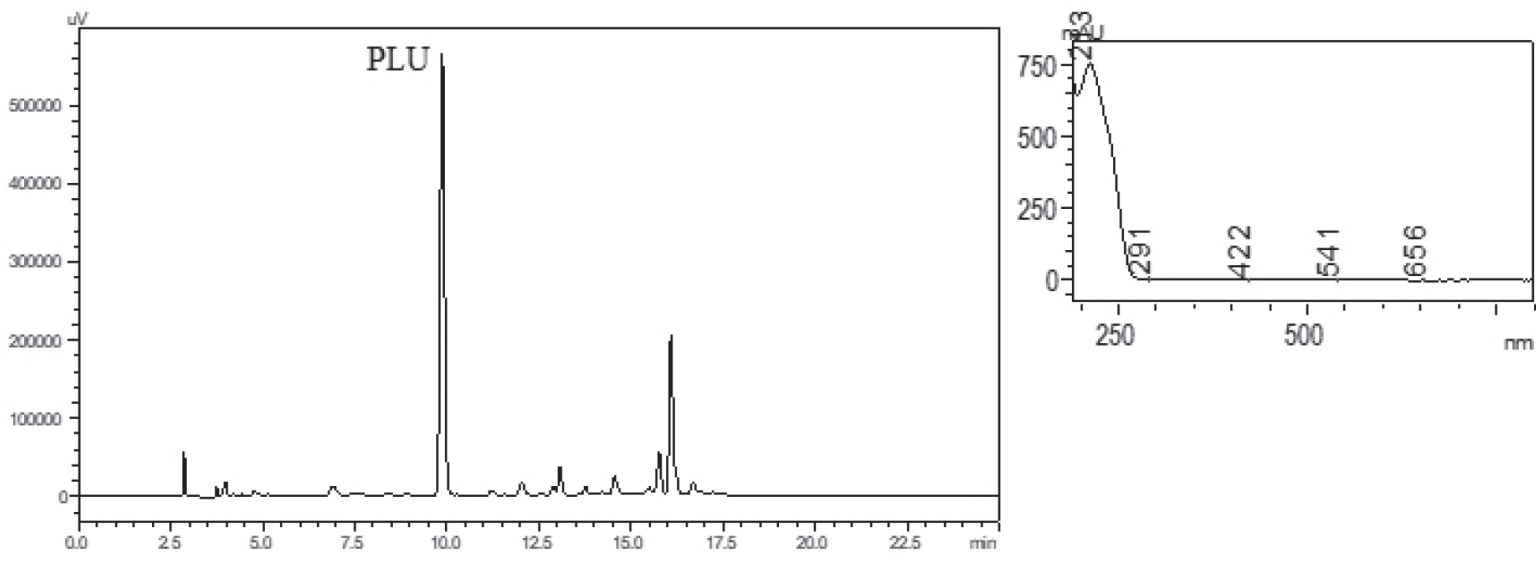

(B) $355 \mathrm{~nm}$
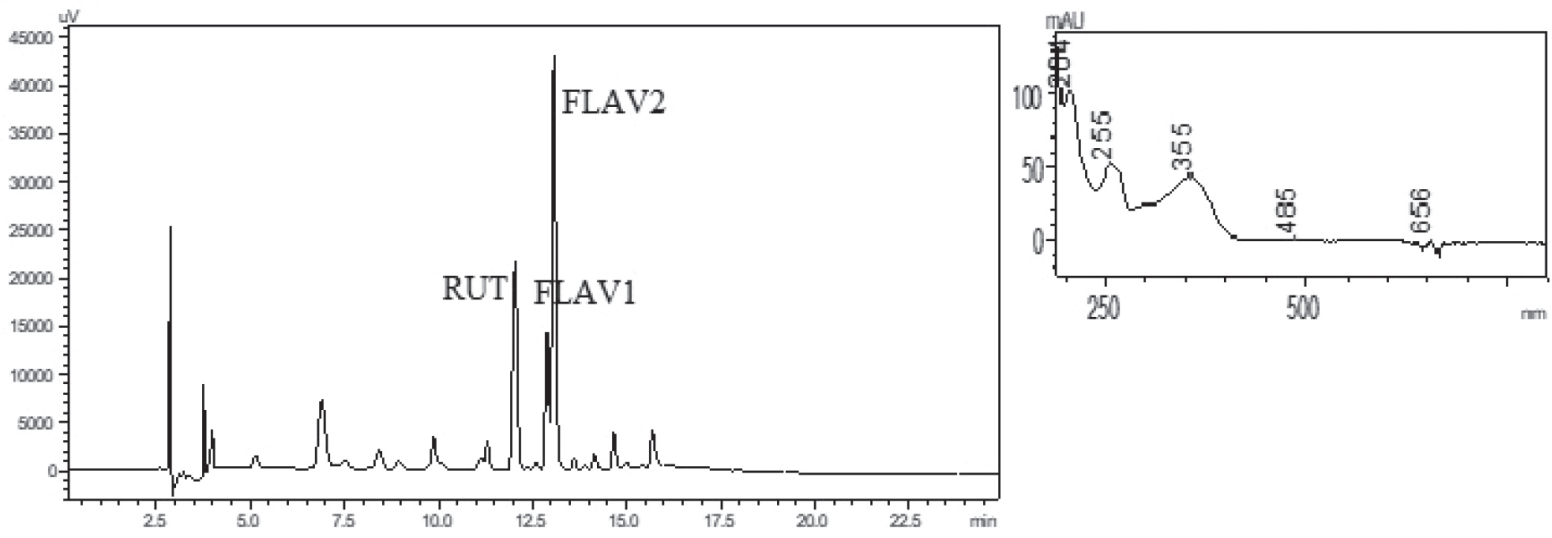

Figure 1. Chromatographic profile of the extractive solution from A. cathartica flowers collected in Itajai (AC02). (A) Chromatogram at $230 \mathrm{~nm}$ showing plumieride (PLU) as a major compound. (B) Chromatogram at $355 \mathrm{~nm}$ showing rutin (RUT) and other flavonoids (FLAV1 and FLAV2) 
(A)

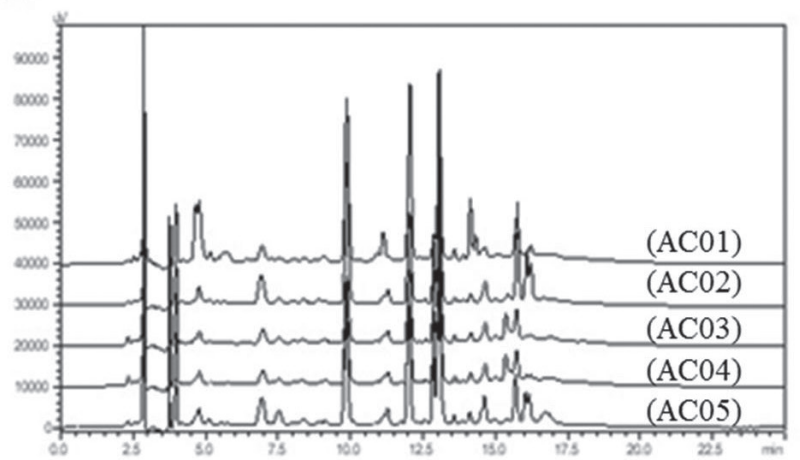

(C)

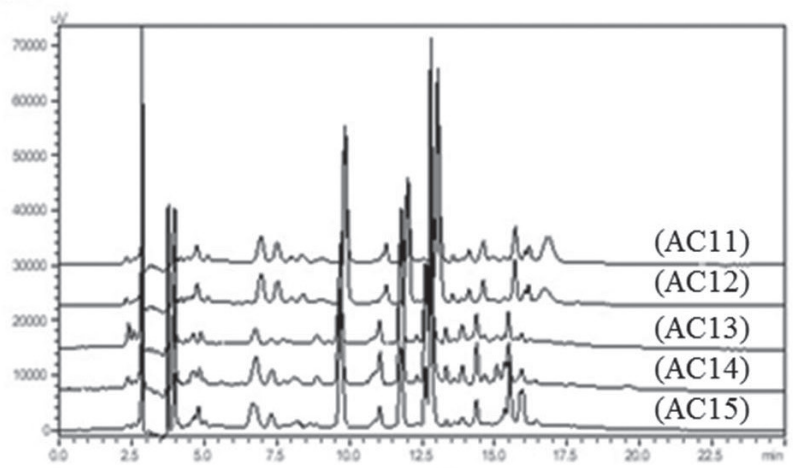

(B)

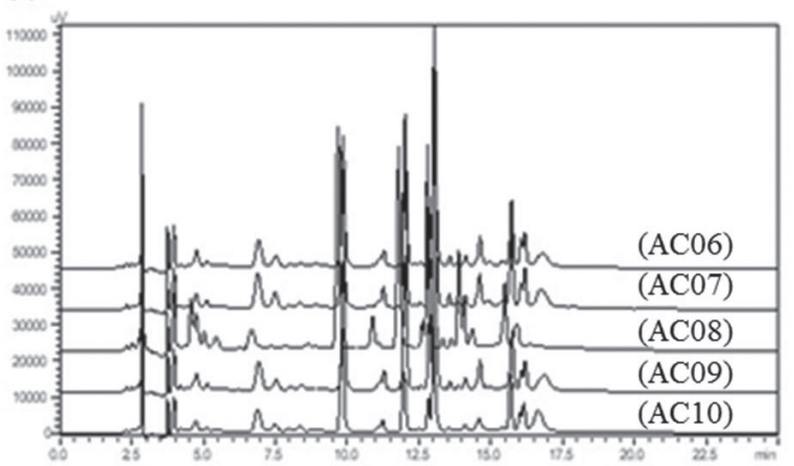

(D)

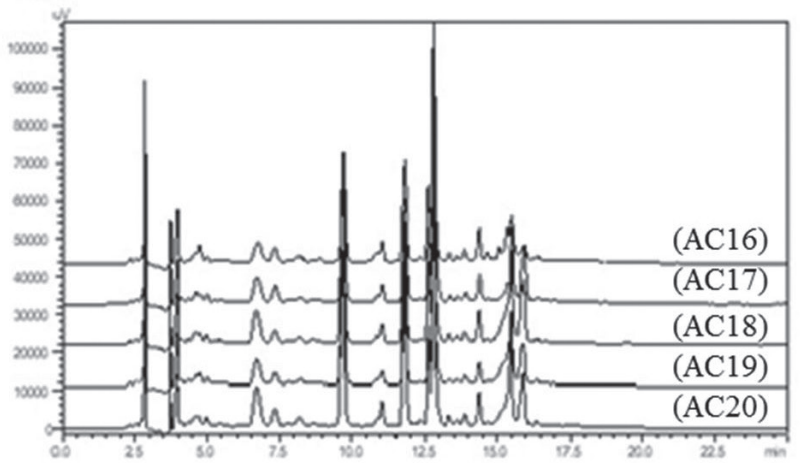

(E)

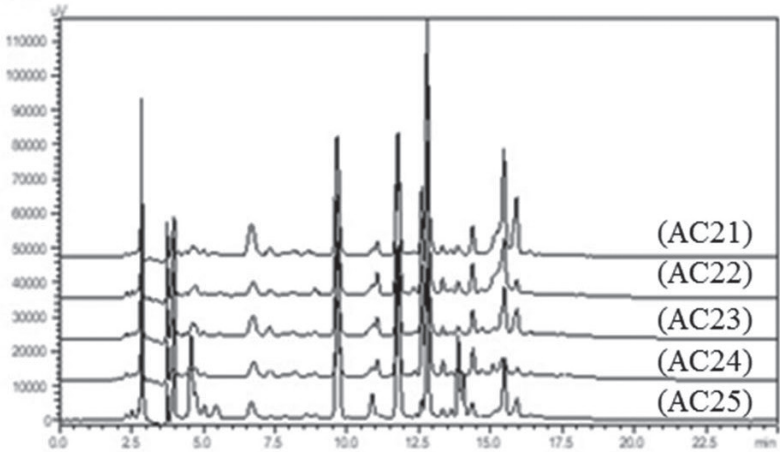

Figure 2. Chromatographic profile of the extractive solution from A. cathartica flowers at $265 \mathrm{~nm}$

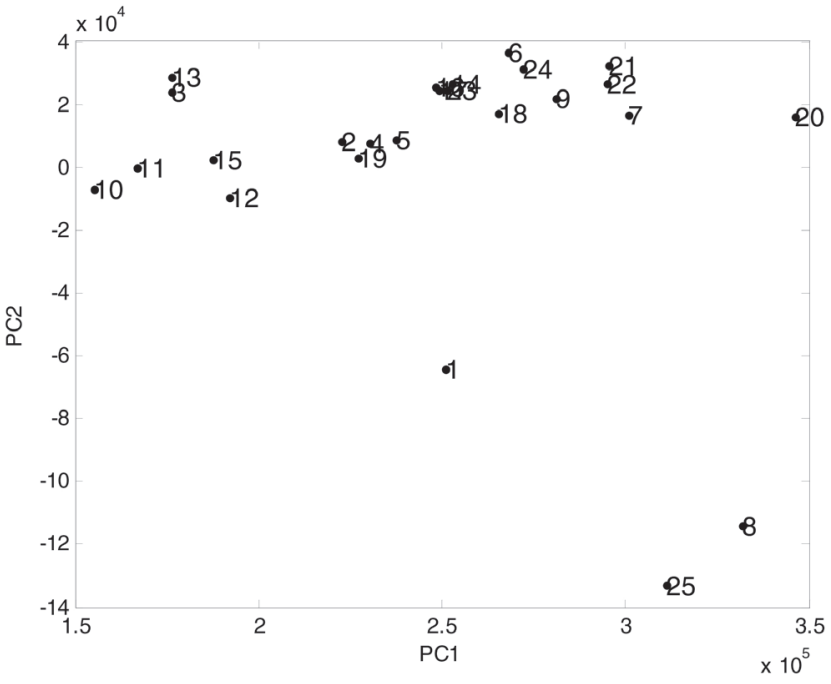

Figure 3. Principal Component Analysis (PCA) of extractive solution chromatogram from A. cathartica flowers from different localities

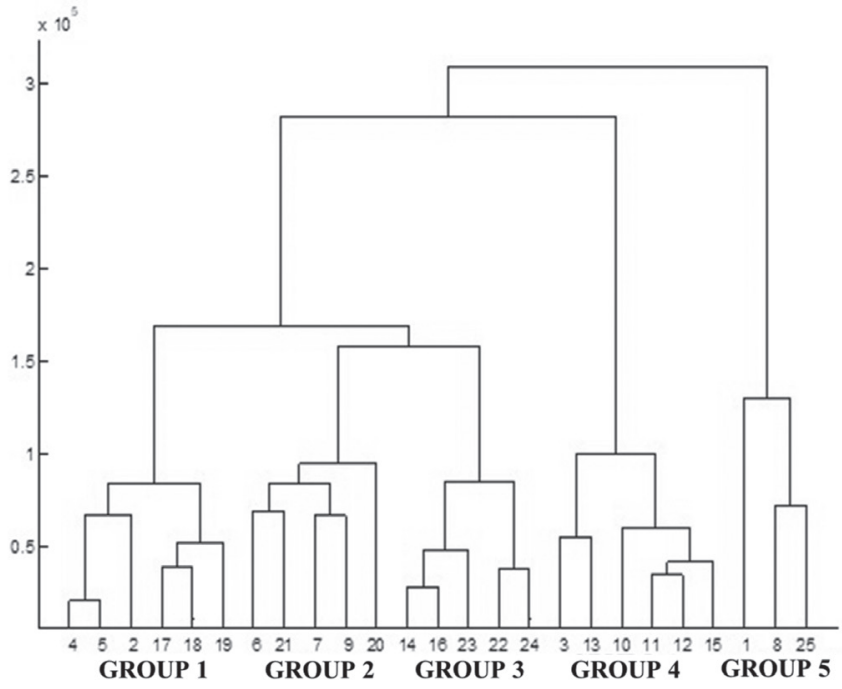

Figure 4. Hierarchical Clustering Analysis (HCA) of extractive solution chromatogram from A. cathartica flowers from different localities 
chemical composition of the flowers is similar, with differences in the plumieride and flavonoid concentrations in the samples. Plumieride was the major substance in all collections, rutin and other flavonoids were also found in smaller amounts. Regarding the dissimilar samples, AC01, AC08 and AC25, collected in Araquari in January, February and March 2017, it was observed that they presented the highest concentrations for the iridoid.

The production of secondary metabolites is related to plant defense mechanisms. This defensive function is considered a milestone in the evolution of photosynthetic eukaryotes..$^{15}$ The transition from aquatic plants to terrestrial plants resulted in biochemical and biogenetic diversifications in the metabolism of these organisms. Paleochemical analyzes of ancestral plants have shown an increase of metabolite diversity of lignin, terpenoid, tannin and flavonoid. This finding is related to abiotic factors and interaction with early arthropods. The amounts of iridoids in plants vary according to genotype and environmental factors. ${ }^{16}$ Iridoids are capable of inhibiting seedling germination and growth, acting against insects and microorganisms. Thus plants that have this type of metabolite can guarantee their survival. All samples used in our study were exposed to sunlight and in urban environments, whether on public roads with vehicle traffic or in gardens.

The Araquari collections (AC01, AC08, AC25), which presented the highest concentrations of the iridoid, are on an unpaved road and with intense cargo transport flow. This feature of the site may be related to the larger production of plumieride iridoid, because even receiving such pollution the flowers keep the yellow aspect, smooth and delicate, without signs of predation or local contamination. When compared to the collection of Navegantes (AC13), which presented the lowest iridoid concentration, the production of this metabolite can also be explained due to the collection site, since the plant was in a residential garden. Thus the lower production of this metabolite shows a lower susceptibility to threats caused by herbivory, for example.

The samples of Araquari (AC01, AC08, AC25) and Camboriú (AC20) presented the highest concentrations of rutin and total flavonoids. The other samples presented similar values. Flavonoids are responsible for many functions in the plants, mainly give color and flavor to flowers and, as in most phenolic compounds, prevent herbivory inhibiting the activity of predatory digestive enzymes. ${ }^{15}$ Flavones and flavonols are chemical protectors in flowers, absorbing shorter light waves lengths, protecting plant cells against photooxidation. Also, these substances are attractive to insects that see in the extreme range of ultraviolet rays. ${ }^{17}$ Especially flavonols, the group to which rutin belongs, are responsible in flowers for forming nectar guides, which are symmetrical patterns of stripes, points or concentric circles. This feature helps insects reach pollen and nectar. Analyzing the results found in this study, it can be stated that the presence of rutin and total flavonoids in the flowers indicate the importance of these metabolites as an active UV protection, considering that this species prefers sunny places. Their inflorescences tend to produce flavonoids as a form of UV protection and ensure their insect pollination.

In 2008, in a study by Huber and Rodriguez-Amaya, it was found that flavonoid concentrations in vegetables increased when grown in summer and that the profiles of these substances are determined by an enzyme system that controls their synthesis and distribution in plants. This behavior added to factors such as season, UV light incidence and soil composition, can influence the flavonoid concentration. ${ }^{18}$ Thus, the flavonoids found in the extracts of A. cathartica flowers have the biological function of guaranteeing the integrity of the flowers that, even in polluted environments, susceptible to insect attack and, especially, to excess light, keep the characteristics of the flowers.

\section{CONCLUSION}

The flowers of Allamanda cathartica collected in different localities showed qualitatively similar chromatographic profiles, with the presence of iridoid plumieride and flavonoids in according to literature. The chemical variability of the samples, assessed by PCA and HCA, highlighted AC01, AC08 and AC25 as the most dissimilar samples. It was observed that this dissimilarity is most related to plumieride content, even higher in the samples highly stressed by human influence. These are important information taking into account the reproducibility and standardization of $A$. cathartica flower extracts.

\section{ACKNOWLEDGMENTS}

This study was supported by government grants from Conselho Nacional de Desenvolvimento Científico e Tecnológico (CNPq) and Fundação de Amparo à Pesquisa e Inovação do Estado de Santa Catarina (FAPESC). Universidade do Vale de Itajaí (UNIVALI) also provided financial support (fellowship).

\section{REFERENCES}

1. Lopes, R. K.; Ritter, M. R.; Rates, S. M. K.; Revista Brasileira de Biociências 2009, 7, 305.

2. Saranya, S.; Chitra, M.; VRI Phytomedicine 2014, 1, 13.

3. Petricevich, V. L.; Abarca-Vargas, R. Molecules 2019, 7, 1238.

4. Sharma, K. K.; Shaikia, J.; Kotoky. J.; K; Kalita, J. C.; Das, J.; Int. J. Pharm. Res. 2011, 3, 644.

5. Nayak, S.; Nalabothu. P.; Sandiford, S.; Bhogadi, V.; Adogwa, A.; BMC Complementary Altern. Med. 2006, 6, 1 .

6. Muller, A. F. F.; Silva, D. C. S.; Macdonald, R.; Bonomini. T. J.; Machado, M. S. M.; Yunes, R. A.; Malheiros, A.; Lucinda-Silva, R. M.; J. Chem. Pharm. Res. 2015, 7, 250.

7. Bonomini, T. J.; Góes, J. A.; Machado, M. S.; Lucinda-Silva, R. M.; Malheiros, A.; Quim. Nova 2018, 41, 36.

8. Boeing, T.; Souza, P.; Bonomini, T. J.; Mariano, L. N. B.; Somensi, L. B.; Lucinda, R. M.; Malheiros, A.; Andrade, S. F.; Biomed. Phamacother. 2018, 99, 697.

9. Silva, K. A. B. S.; Dissertação de Mestrado, Universidade Federal de Santa Catarina, Brasil, 2007.

10. Tiwari, T. N.; Pandey, V. B.; Dubey, N. K.; Phytother. Res. 2002, 16, 393.

11. Gonçalves, C. F. L.; Santos. M. C. S.; Ginabreda, M. G.; Fortunato, R. S.; Carvalho, D. P.; Ferreira, A. C. F.; PloS One 2013, 8, 1.

12. Gobbo-Neto, L.; Lopes, N. P.; Quim. Nova 2007, 30, 374.

13. Farmacopéia Brasileira. $5^{\text {th }}$ ed., Anvisa: Brasília, 2010.

14. Klein-Júnior, L. C; Viaene, J.; Salton, J.; Koetz, M.; Gasper, A. L.; Henriques, A. T.; Heyden, Y. V.; J. Chromatogr. A 2016, 1463, 60.

15. Kariñho-Betancourt, E.; Bot. Sci. 2018, 96, 35.

16. Bowers, M. D. Em Herbivores: Their interactions with secondary plant metabolites; Rosenthal, G. A.; Berenbaum, M. R., eds.; Academic Press: San Diego, 1991, cap. 8.

17. Ferreira, M. M. M.; Oliveira, A. H. C. de.; Santos, N. S.; Agro@mbiente On-line 2008, 2. 57.

18. Huber, L. S.; Rodriguez-Amaya, D. B.; Alim. Nutr. 2008, 19, 97. 